\title{
Effects of Pulse Frequency on Performance of Electrochemical Cooling Water Treatment for Cooling Tower of Water-Cooled Chiller
}

\author{
Le Minh Nhut ${ }^{1}$, Duong Huynh Minh Nhut ${ }^{2}$ \\ ${ }^{1}$ Department of Thermal Engineering \\ Faculty of Vehicle and Energy Engineering \\ Ho Chi Minh City University of Technology and Education \\ No 1 Vo Van Ngan Street, Thu Duc District, Ho Chi Minh City, Vietnam \\ Phone number: +84978 446 968, e-mail: nhutlm@hcmute.edu.vn \\ ${ }^{2}$ College of Technology II, Ho Chi Minh City, Vietnam \\ E-mail: nhut.duonghuynh@gmail.com
}

\begin{abstract}
Due to the rapid economic development in recent years, water-chiller is being used more and more in hotels, restaurants, resorts, and industrial zones in Vietnam. The cooling tower's cooling water quality is an important factor in determining the effect on electrical consumption and the coefficient of performance of a water-cooled chiller. Therefore, it is necessary to maintain the quality of cooling water during the operation time of the water-cooled chiller. The aim of this work is to investigate the effects of the pulse frequency and operational parameters such as current density, pulse duty cycle, and energy consumption on the performance of removing hardness ion of electrochemical cooling water treatment for the cooling tower of the water-cooled chiller. The results show that the highest efficiency of the total hardness removal corresponding to a pulse frequency of $1 \mathrm{kHz}$, a pulse duty cycle of 0.7 , and a current density of $80 \mathrm{~A} / \mathrm{m}^{2}$.
\end{abstract}

Key words. Pulse frequency; Cooling tower; Cooling water; Hardness removing; Water-cooled chiller

\section{Introduction}

Cooling towers are an integral component of many water-cooled chillers, which are used to reject the waste heat of the condenser. The coefficient of performance (COP) is an important factor of the water-cooled chillers that is mainly influenced by the quality of cooling water of the cooling towers. Therefore, there are currently several studies using various technologies such as softening, chemicals, and electrochemical technology for the treatment of the cooling water of cooling towers, but electrochemical technology is focused because there are many advantages such as simple, inexpensive, and long life.

Several investigations in cooling water treatment theories for the cooling tower were mentioned in the literature [1-3]. Hussein et al. [4] presented the efficiency of the electrocoagulation (EC) technology with the magnesium-rod electrode in the removal of hardness ions of cooling tower blowdown (CTB). They concluded that the maximum removal efficiency of $51.80 \%$ and $93.70 \%$ can be obtained for hardness ions and silica. The removal mechanism of electrochemical cooling water of cooling tower were reviewed in the literature $[5,6]$. The constructed wetlands, and the combination of electrochemical oxidation and constructed wetlands have been suggested for the removal of organic compounds from CTB in the cooling tower $[7,8]$. The performance of $\mathrm{EC}$ using $\mathrm{Al}, \mathrm{Fe}$, and $\mathrm{Zn}$ electrodes in the removal of hardness ions from CTB was studies by Hafez et al. [9]. Saha et al. [10] evaluated the performance of electrochemical oxidation (EO) with a boron-doped diamond (BDD) anode to remove organic compounds (OCs) from CTB in the cooling tower. Liao et al. [11] reported that the efficiency of hardness ion removal for the cooling tower blowdown in the cooling tower can be improved by the $\mathrm{EC}$ using $\mathrm{Fe}$ and $\mathrm{Al}$ electrodes, and the addition of coagulation aids.

Several studies have recently focused on pulse electrocoagulation technology for improving the efficiency of hardness removal from cooling water in cooling towers, as follows. Performance of pulse electro-coagulation technology using $\mathrm{Fe}$ electrode applied to berberine pharmaceutical $(\mathrm{BH})$ wastewater treatment has been reported [12]. The results indicated that the removal efficiencies of BH and COD could be obtained at $72.8 \%$ and $69.6 \%$, respectively. Yao et al. [13] studies the thickness of the ceramic coatings of Ti-6Al-4V alloys by pulsed plasma electrolytic oxidation. Response surface methodology (RSM) was used to evaluate the effects of several parameters, such as pulse duty cycle, power frequency and current density, on the efficiency of electrochemical oxidation system using the boron-doped diamond as anode material in the system [14]. RSM was also investigated to reduce energy consumption during the pulsed EO process by using graphite electrodes [15]. Wang et al. [16] reported the optimized method of the operating parameters of the EO under pulse mode for treatment recalcitrant dye wastewater to improve the TOC degradation and the energy consumptions. A study on the different pulse waveforms in pulse electrodepositing for platinum catalyst has been investigated [17]. The types of $\mathrm{Pt} / \mathrm{C}$ electrodes, $\mathrm{PbO}_{2}$ anode, and Ni-rich electrolytes in the pulse EO 
technology were considered [18-21]. A paper by Chen [22], who investigated an electrosorption enhanced electrooxidation of a model organic pollutant at 3D SnO2$\mathrm{Sb}$ electrode in superimposed pulse current mode, looked at operational parameters, such as the removal efficiency, the energy consumption, the instantaneous pulse current, and accumulated degradation intermediates.

From the above literature review, even though there have been a lot of researches on cooling water treatment by electrochemical technology for cooling tower, however, there has not been a study to meet the quality standard of cooling water for cooling towers in Vietnam. Hence, this present study investigated the effects of pulse frequency of electrochemical technology on the efficiency of total hardness removal of cooling water to obtain the required cooling water quality for cooling tower operation of watercooled chiller according to the water quality standards TCXD 232:1999 of Vietnam (the properties of cooling water were: total hardness (such as $\mathrm{CaCO}_{3}$ ) $280 \mathrm{ppm}, \mathrm{pH}$ 7.6; total dissolved solids (TDS) 402-407 ppm). Besides, the effects of operational parameters such as the pulse duty cycle, current density, and energy consumption on total hardness removal efficiency are considered.

\section{Materials and experiment \\ 2.1 Electrolysis process and pulse potential}

The electrolysis process of cooling water is the decomposition of water into oxygen and hydrogen gas due to the passage of an electrical current, creating an alkaline environment at the cathode that raises the $\mathrm{pH}$ in the vicinity of the electrode surface and promotes precipitation of the calcium hardness in form of $\mathrm{CaCO}_{3}$ according to the reaction as follows [3, 6, 23-25].

Anode reaction (positive electrode), oxidation of water:

$$
2 \mathrm{H}_{2} \mathrm{O}-4 \mathrm{e}^{-} \rightarrow \mathrm{O}_{2}+4 \mathrm{H}^{+}
$$

Cathode reaction (negative electrode), decomposition of water:

$$
4 \mathrm{H}_{2} \mathrm{O}+4 e^{-} \rightarrow 2 \mathrm{H}_{2} \uparrow+4 \mathrm{OH}^{-}
$$

In hard water containing bicarbonate ions a secondary reaction occurs in the anode, secondary anode reactions:

$$
\mathrm{H}^{+}+\mathrm{HCO}_{3}^{-}+\mathrm{H}_{2} \mathrm{CO}_{3} \rightarrow 2 \mathrm{CO}_{2} \uparrow+2 \mathrm{H}_{2} \mathrm{O}
$$

In hard water containing bicarbonate ions and calcium ions, two secondary reactions occur in the cathode:

$$
\begin{aligned}
& \mathrm{OH}^{-}+\mathrm{HCO}_{3}^{-} \rightarrow \mathrm{CO}_{3}^{2-}+\mathrm{H}_{2} \mathrm{O} \\
& \mathrm{Ca}^{2+}+\mathrm{CO}_{3}^{2-} \rightarrow \mathrm{CaCO}_{3} \downarrow
\end{aligned}
$$

In this study, the pulse electrochemical cooling water is carried out with a pulsed DC power supply mode. The output of pulsed DC power supply mode is rectangular waveform pulse potential, as shown in Figure 1. The pulse cycle (total pulse period) $\mathrm{T}$ is the sum of a turn-on time $\mathrm{T}_{\text {on }}$ and a turn-off time $\mathrm{T}_{\text {off. }}$. The $\mathrm{T}_{\text {on }}$ is the duration time of the pulsed DC power is switched on as constant amplitude of potential while $T_{\text {off }}$ is the intermittent time of the pulsed DC power is switched off. The relationship between the pulse duty cycle $\gamma$ (Equation 6), the pulse cycle T, and the pulse frequency $\mathrm{f}$ (Equation) are expressed as [9, 13-14, 17, 26-27]:

$$
\gamma=\frac{T_{Q n}}{T}=\frac{T_{Q n}}{T_{Q n}+T_{Q f f}}
$$

$$
f=\frac{1}{T}=\frac{1}{T_{o n}+T_{o f f}}
$$

Water treatment efficiency is calculated as follows [28]:

$$
R=\frac{C_{t n}-C_{o u t}}{C_{t n}} \times 100 \%
$$

Where $\mathrm{R}(\%)$ is the percentage of hardness removal, $\mathrm{C}_{\text {in }}$ (ppm) is initial concentration, and $\mathrm{C}_{\text {out }}(\mathrm{ppm})$ is concentration after treatment.

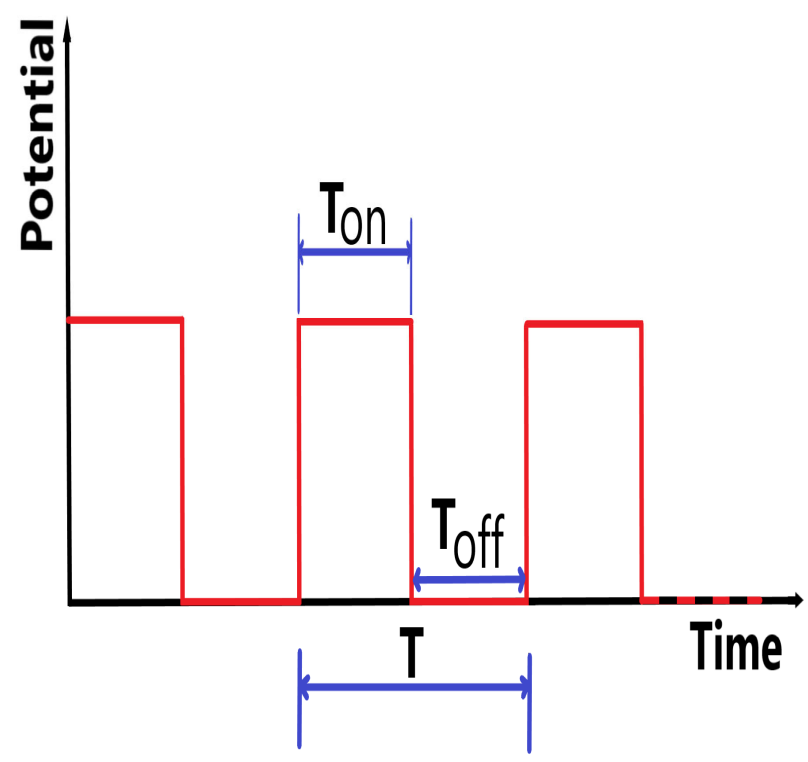

Fig.1. Pulse potential waveform

\subsection{Experimental set-up and procedure}

Figure 2 shows the schematic diagram of the pulse electrochemical cooling water treatment for the cooling tower of the water-cooled chiller. This system was designed and installed on the campus of the Ho Chi Minh City of University of Technology and Education, Vietnam. It mainly consists of a pulsed DC power supply mode, a cooling tower, a condenser connected with the cooling tower, an electrochemical reactor tank and electrodes, and two pumps for condenser loop and electrochemical reactor tank loop, measuring devices, and control box. The vertical type electrochemical reactor tank has $2 \mathrm{~L}$ capacity. The electrodes are made from titanium mesh and have a reaction area of $145 \mathrm{~cm}^{2}$ per plate, and are installed in parallel. The anode is coated with lead dioxide $(\mathrm{PbO} 2)$. The cooling tower has a capacity of $5 \mathrm{RT}$, while the condenser has a capacity of $21.3 \mathrm{~kW}$ connected with the cooling tower. There are two pumps in the system, one circulation pump has a capacity of $85 \mathrm{~W}$ for the condenser loop, and another pump has a capacity of $65 \mathrm{~W}$ for the electrochemical reactor tank loop. The pulsed DC power supply can be adjusted to the pulsed potential according to the experiments.

The cooling water quality after the treatment needs to be obtained the required water quality for cooling tower operation of water-cooled chiller according to the water quality standards TCXD 232:1999 of Vietnam (the properties of cooling water were: total hardness (such as $\mathrm{CaCO}_{3}$ ) less than $240 \mathrm{mg} / \mathrm{l}$. The total hardness was 
measured with a HI3812 (Hanna-USA), and the total dissolved solids (ppm) was measured by a TDS-04 meter (Total Meter-Taiwan). A pH-2 meter (Mudder) and a power meter (PZEM-002) were used to measure the $\mathrm{pH}$ index and the energy consumption during the operation. The data of the system is recorded during an experimental session and temporarily stored in an Excel file on the controlling $\mathrm{PC}$ and is available for downloading for subsequent calculation. The Experimental set-up diagram is shown in Figure 3.

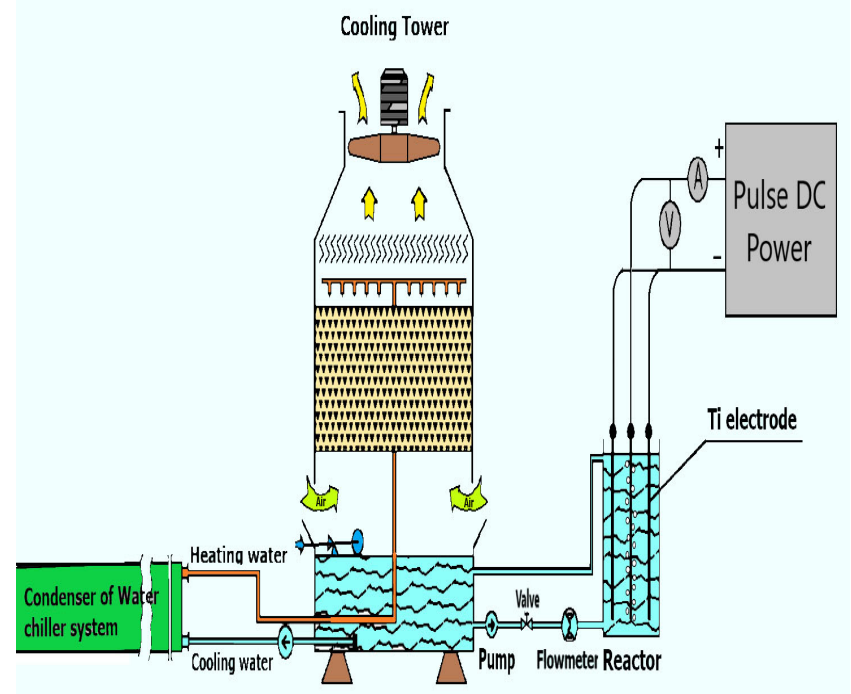

Fig.2. Schematic diagram of the pulse electrochemical cooling water treatment system
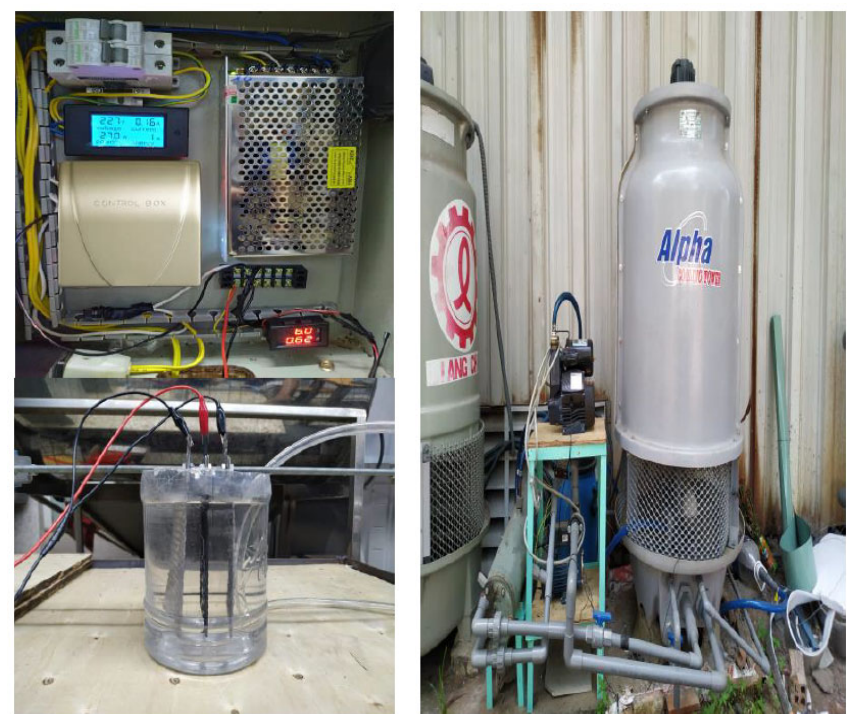

Fig. 3. The Experimental set-up used for the pulse electrochemical cooling water treatment system

\section{Results and discussion}

Figure 4 shows the change in the efficiency of the total hardness removal during the reaction period of pulse frequency. With the increase of the pulsed frequency ranges from $0.1 \mathrm{kHz}$ to $30 \mathrm{kHz}$, the efficiency of the total hardness removal increased gradually at the beginning and reached the highest value of $86 \%$ at the pulse frequency of $1 \mathrm{kHz}$. This was due to an increase in the pulse frequency range of $0.1 \mathrm{kHz}$ to $1.0 \mathrm{kHz}$, which led to a decrease in the time of power-on and DC power-off, during which time the metal ions transported rapidly and the metal ions became metal on the cathode. While the increase in the pulse frequency is higher than $1.0 \mathrm{kHz}$, there is a rapid decrease in the total hardness removal. This was due to the time of DC power-on and DC power-off time increase, the pulse diffusion layer is made up which impeded the moving of metal ions to the cathode $[9,16,19]$.

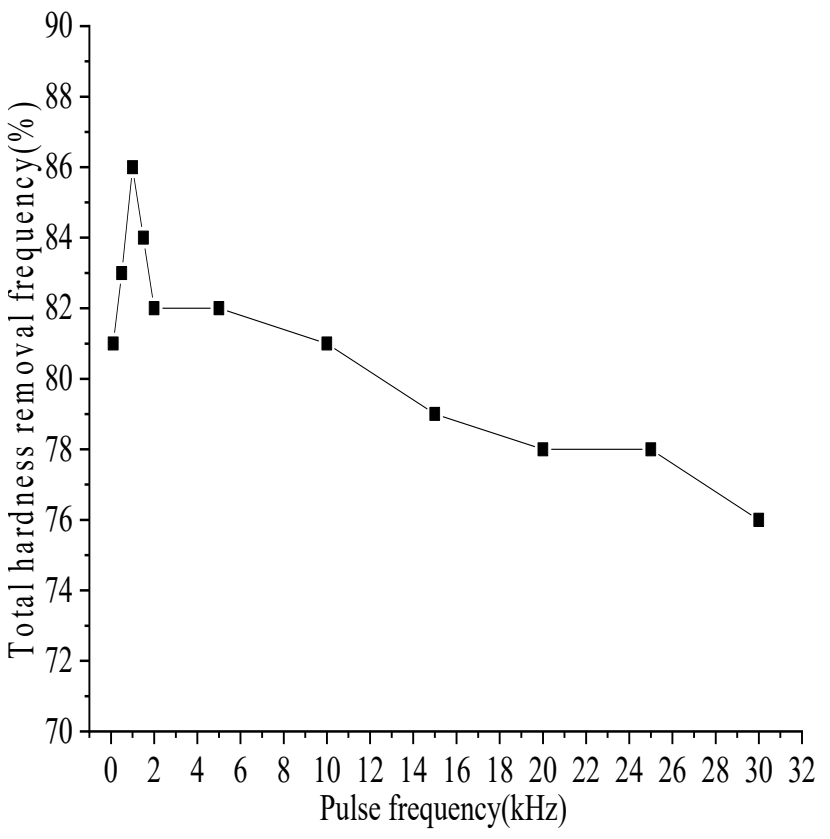

Fig.4. Effect of pulse frequency on efficiency of total hardness removal

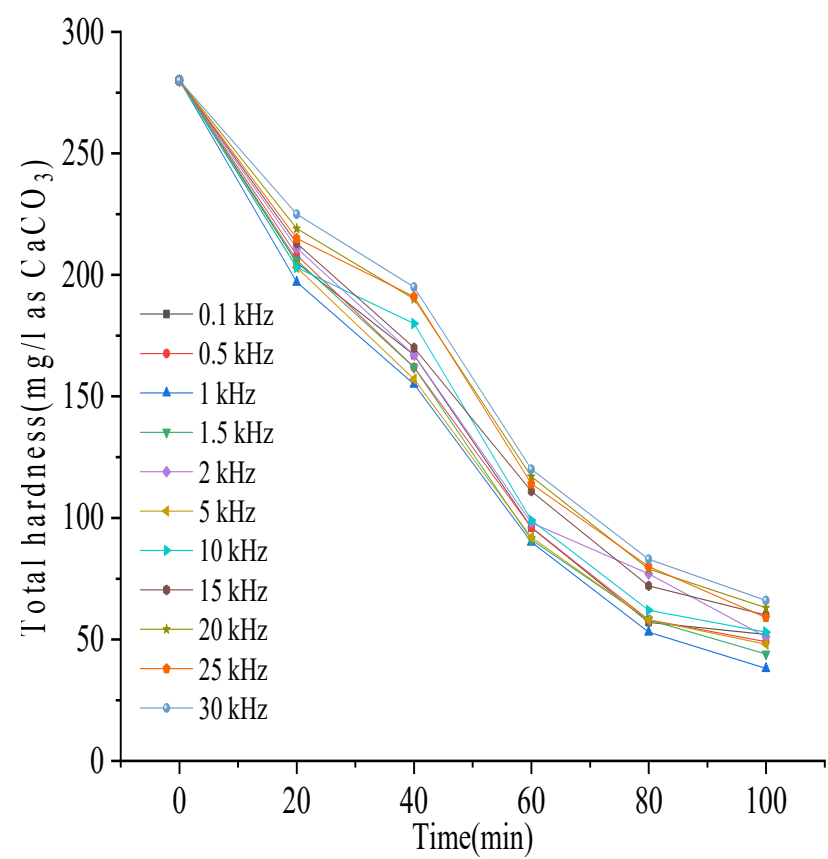

Fig. 5. Effect of pulse frequency on total hardness 
Figure 5 shows the effect of pulse frequency on total hardness. As seen in Fig.5, during the first 60 minutes, when the concentration of hardness ions in the cooling water is high, the electrolysis reaction occurs rapidly leading to a rapid decrease in total hardness, and then the total hardness decreased gradually due to the concentration of hardness ions decrease leads to the decline of electrolysis reaction. There is not much difference in the reduction of total hardness when the pulse frequency changes from $0.1 \mathrm{kHz}$ to $30 \mathrm{kHz}$. The lowest value of total hardness is $38 \mathrm{mg} / \mathrm{l} \mathrm{CaCO} \mathrm{Ca}_{3}$ achieved at $1 \mathrm{kHz}$, corresponding to an electrolysis time of 100 minutes.

The effect of pulse frequency on the TDS index (Total Dissolved Solids) was shown in Fig.6. There is no difference in the reduction of TDS index when the pulse frequency ranges from $0.1 \mathrm{kHz}$ to $30 \mathrm{kHz}$. During the first 60 minutes, the TDS index rapidly decreased and then gradually decreased with electrolysis time. At the pulse frequency of $1 \mathrm{kHz}$, the TDS index dropped the fastest at 1 $\mathrm{kHz}$ from $403 \mathrm{mg} / \mathrm{l}$ to $126 \mathrm{mg} / \mathrm{l}$. The low TDS index indicated that the metal ions such as $\mathrm{Ca}^{2+}$ and $\mathrm{Mg}^{2+}$ in the cooling water are low.

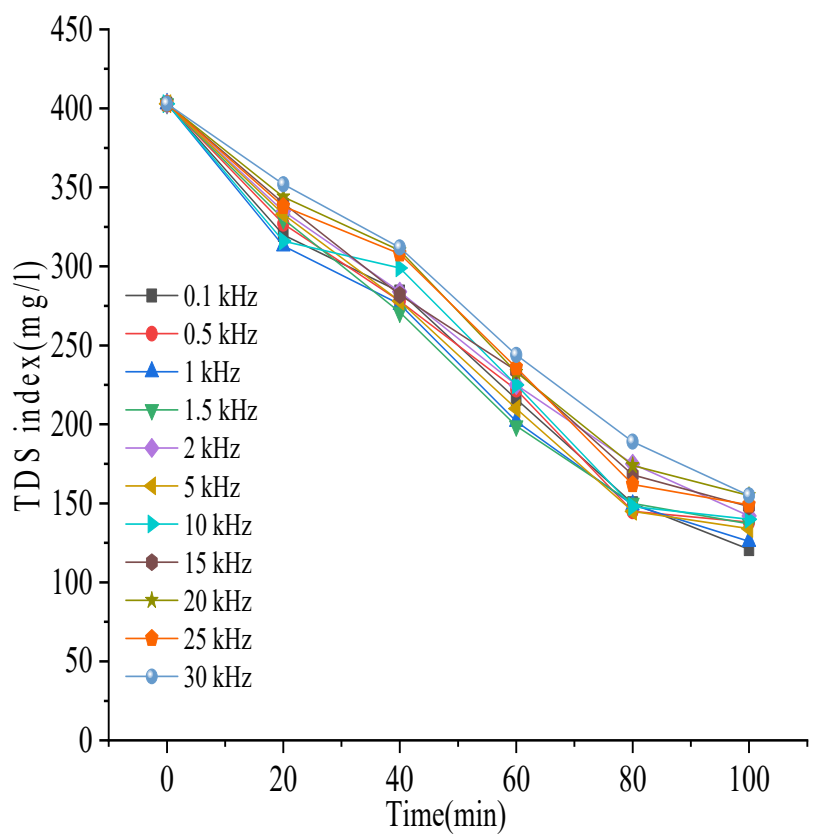

Fig. 6. Effect of pulse frequency on TDS index (Total Dissolved Solids)

The effect of the pulse duty cycle on the efficiency of the total hardness removal and energy consumption was shown in Figure 7. By increasing the pulse duty cycle from 0.2 to 0.7 leads to increase sharply the efficiency of total hardness removal and reached the highest point of above $88 \%$ at the pulse duty cycle of 0.7 . Then with the continual increase of the pulse duty cycle above 0.7 , the efficiency of total hardness removal is constant. Whereas the energy consumption gradually increased from 35 to $52 \mathrm{Wh}$.

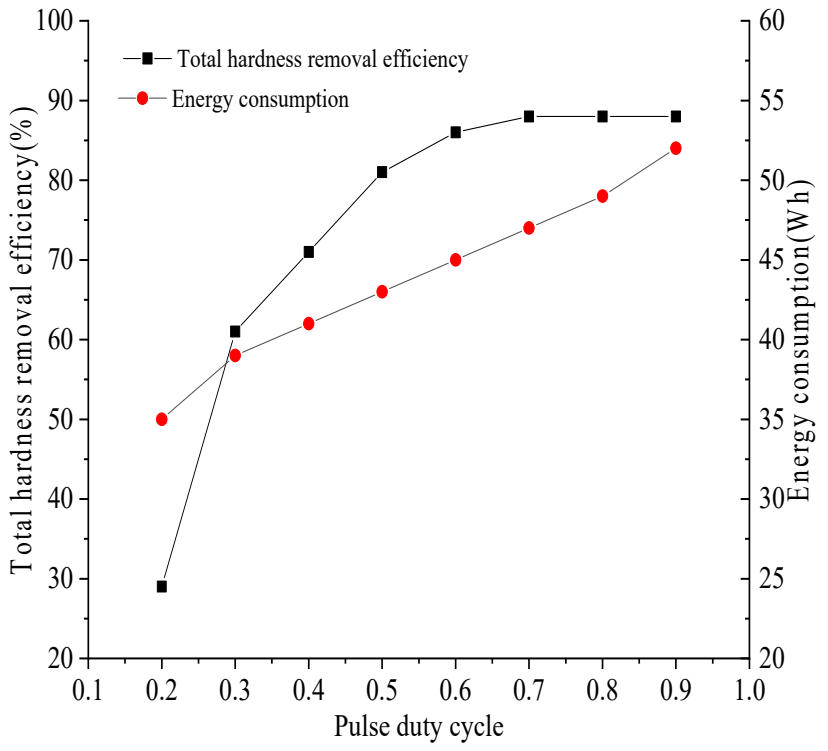

Fig.7. Effect of pulse duty cycle on total hardness removal efficiency and energy consumption

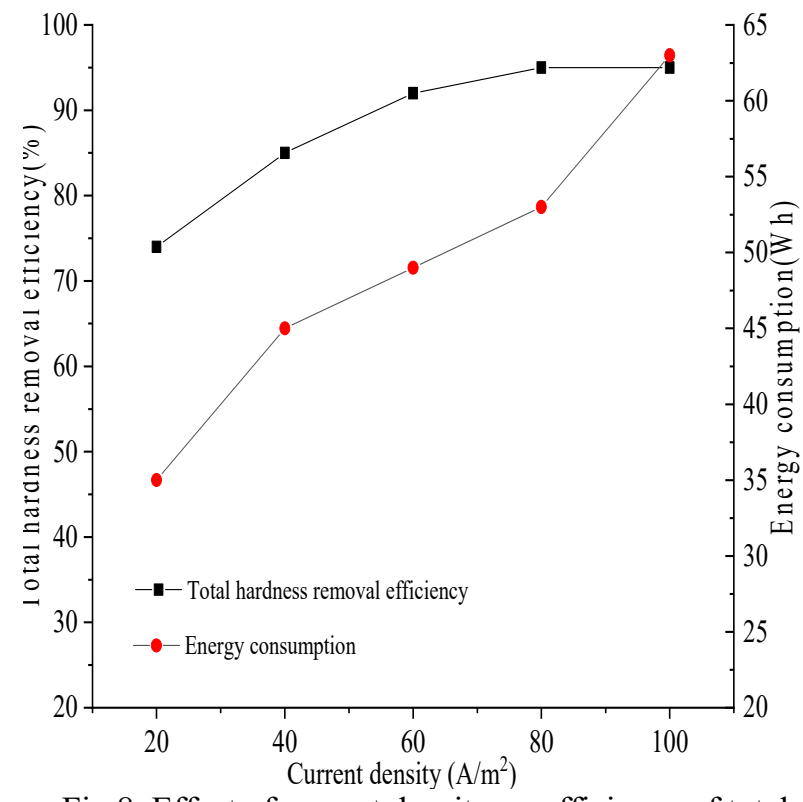

Fig.8. Effect of current density on efficiency of total hardness removal and energy consumption

Figure 8 shows the effect of current density on efficiency of total hardness removal and energy consumption. As indicated in Figure 8, once the current density ranges from $20 \mathrm{~A} / \mathrm{m}^{2}$ to $80 \mathrm{~A} / \mathrm{m}^{2}$, the efficiency of total hardness removal increases from $74 \%$ to $95 \%$, and the energy consumption increases from $35 \mathrm{Wh}$ to $53 \mathrm{Wh}$. When the current density grows more massive than $80 \mathrm{~A} / \mathrm{m}^{2}$, the efficiency of total hardness removal tends to be steady, while energy consumption continuously increased. This is because the electrochemical mechanism, the more $\mathrm{OH}^{-}$ is produced on the cathode, and the electrochemical ions are enhanced by an increase in the current density, which leads to harder ions precipitating on the cathode surface. Then the rate of the precipitation increases slowly. The efficiency of total hardness removal reached the highest point of above $95 \%$ at $80 \mathrm{~A} / \mathrm{m}^{2}$. 


\section{Conclusion}

In this study, the effects of the operating parameters such as pulse frequency, current density, pulse duty cycle, and energy consumption on the performance of hardness removal of electrochemical cooling water treatment for cooling tower of water-cooled chiller was evaluated. For the purpose of the quality of the cooling water after the treatment was obtained the required water quality of the water quality standards TCXD 232:1999 of Vietnam.

The results showed that the efficiency of total hardness removal is highest at the pulse frequency is $1.0 \mathrm{kHz}$, the pulse duty cycle is 0.7 , and the current density is $80 \mathrm{~A} / \mathrm{m}^{2}$.

\section{Acknowledgement}

The authors would like to thanks for the support from Ho Chi Minh City University of Technology and Education, Ho Chi Minh City, Vietnam.

\section{References}

[1] W. Herbert, III. Stanford, HVAC water chillers and cooling towers: Fundamentals, Application, and Operation, Second ed, Taylor\&Francis Group, 2012.

[2] C. Gabrielli, et al, "Electrochemical water softtening: principle and application", Desalination (2006). Vol. 201, pp. $150-163$.

[3] A. Bannoud, "The electrochemical way of removing the hardness of water", Desalination (1993). Vol. 93, pp. 545-555.

[4] I.A.S. Hussein, "Electrochemical treatment of industrial cooling tower blowdown water using magnesium-rod electrode", Water Resources and Industry (2020). Vol. 92, 100121.

[5] X. Hao, et al ". Research and application progress of electrochemical water quality stabilization technology for recirculating cooling water in China: A short review", Journal of Water Process Engineering (2020). Vol. 37, 101443.

[6] H. A. Becker, J.J. Cohen and A.D.Zdunek "Electrochemical cooling water treatment: A new strategy for control of hardness, scale, sludge and reducing water usage", ASHRAE Transactions (2009), Vol. 115, Park 1. Pp. 384-392.

[7] V.T. Wagner, et al "A review on the removal of conditioning chemicals from cooling tower water in constructed wetlands", Critical Reviews in Environmental Science and Technology (2018). Vol. 48, pp. 1094-1125.

[8] P. Saha, et al "Cooling tower water treatment using a combination of electrochemical oxidation and constructed wetlands", Process Safety and Environmental Protection (2020). Vol. 144, pp. 42-51.

[9] O.M. Hafez and M.A, Shoeib "Removal of scale forming species from cooling tower blowdown water by electrocoagulation using different electrodes", Chemical Engineering Research and Design (2018). Vol. 136, pp. 347-357. [10] P. Saha, et al "Removal of organic compounds from cooling tower blowdown by electrochemical oxidation: Role of electrodes and operational parameters", Chemosphere (2020). Vol. 259, 127491.

[11] Z. Liao, et al "Treatment of cooling tower blowdown water containing silica, calcium and magnesium by electrocoagulation", Water Science \& Technology (2009). Vol. 23, pp. 2345-2352.

[12] M. Ren, et al "Treatment of berberine hydrochloride wastewater by using pulse electro-coagulation process with $\mathrm{Fe}$ electrode", Chemical Engineering Journal(2011). Vol. 169, pp. 84-90.

[13] M. Yao, et al "Effects of cathode pulse at high frequency on structure and composition of $\mathrm{Al} 2 \mathrm{TiO} 5$ ceramic coatings on $\mathrm{Ti}$ alloy by plasma electrolytic oxidation", Materials Chemistry and Physics (2011). Vol. 126, pp. 227-231.

[14] J. Wei, X. Zhu and J, Ni "Electrochemical oxidation of phenol at boron-doped diamond electrode in pulse current mode", Electrochimica Acta (2011). Vol. 56, pp. 5310-5315.

[15] N.D. Mu'azu, et al "Specific energy consumption reduction pulsed electrochemical oxidation of phenol using graphite electrodes", Journal of Environmental Chemical Engineering (2016). Vol. 4, pp. 2477-2486.

[16] J. Wang, et al "Multivariate optimization of the pulse electrochemical oxidation for treating recalcitrant dye wastewater", Separation and Purification Technology (2020). Vol. 230, 115851.

[17] S. Karimi and F.R. Foulkes "Pulse electrodeposition of platinum catalyst using different pulse current waveforms", Electrochemistry Communications (2012). Vol. 19, pp. 17-20.

[18] F. Ye, et al "Effect of pulse electrodeposition parameters on electrocatalytic the activity of methanol oxidation and morphology of $\mathrm{Pt} / \mathrm{C}$ catalyst for direct methanol fuel cells", Energy Conversion and Management (2018). Vol. 160, pp. 8592.

[19] F. Ye, et al "Mechanism and kinetic study of pulse electrodeposition process of $\mathrm{Pt} / \mathrm{C}$ catalysts for fuel cells", Renewable Energy (2020). Vol. 145, pp. 514-520.

[20] L. Jiani, et al "Pulse electrochemical oxidation of acid red $\mathrm{G}$ and crystal violet by $\mathrm{PbO} 2$ anode", Renewable Energy (2020). Vol. 8, 103773.

[21] A. Marlot, et al ". Pulse plating of Ni-Mo alloys from Nirich electrolytes”, Electrochimica Acta(2002). Vol. 48, pp. 2936.

[22] Y. Chen, et al "Electrosorption enhanced electrooxidation of a model organic pollutant at $3 \mathrm{D} \mathrm{SnO} 2-\mathrm{Sb}$ electrode in superimpsed pulse current mode", Chemosphere (2018). Vol. 195, pp. 63-69.

[23] H. Jin, et al "Polarity reversal electrochemical process for water softening", Purification Technology (2019). Vol. 201, pp. 943-949.

[24] D. Hasson, et al "Development of the electrochemical scale removal technique for desalination applications", Desalination (2018). Vol. 230, pp. 329-342.

[25] O. Devos, et al "Nucleation-Growth process of scale electrodeposition influence of the supersaturation", Journal of The Electrochemical Society (2003). Vol. 150, pp. C494-C501.

[26] E.M.D. Pena and S. Roy "Electrodeposited copper using direct and pulse currents from electrolytes containing low concentration of additives", Surface \& Coatings Technology (2018). Vol. 339, pp. 101-110.

[27] M.Y. Lin and L.M. Hourng "Effects of magnetic field and pulse potential on hydrogen production via water electrolysis", Int. J. Energy Research (2014). Vol. 38, pp. 106-116.

[28] J.S. Park, et al "Removal of hardness ions from tap water using electromembrane processes", Desalination (2007). Vol. 202, pp. 1-8.

[29] The water quality standards TCXD 232:1999 of Vietnam", 